\title{
Research on the Status Quo of Chinese Martial Arts in Primary School--A Case Study of Some Primary Schools in Qiongshan District, Haikou City
}

\author{
Zhuang Changkuang, Xiao Qian \\ Institute of Physical Education, Hainan Normal University, Haikou, China \\ Email address: \\ 397031977@qq.com (Zhuang Changkuang),1039147513@qq.com (Xiao Qian)
}

To cite this article

Zhuang Changkuang, Xiao Qian. Research on the Status Quo of Chinese Martial Arts in Primary School--A Case Study of Some Primary

Schools in Qiongshan District, Haikou City. International Journal of Elementary Education. Vol. 6, No. 5, 2017, pp. 42-46.

doi: $10.11648 /$ j.ijeedu.20170605.11

Received: October 30, 2017; Accepted: November 28, 2017; Published: January 4, 2018

\begin{abstract}
Based on QiongShan area some primary schools in haikou city as the research foundation, research and analysis of the elementary cognition of wushu culture and wushu interest, study, martial arts in the elementary school student sources and publicity as well as the current situation of teaching management, student sources is relatively narrow, propaganda is small, not enough very clear understanding of wushu culture, and teaching management is not scientific, the teachers strength is not strong.
\end{abstract}

Keywords: Qiongshan District, Primary School, Martial Arts, Interest

\section{Introduction}

The school is an important institution of education, and the ability of various projects to occupy a place in the school is also an important reference for measuring the development of the project. The ability of wushu to enter the campus and the development of the campus is also one of the most important symbols to measure the status of martial arts. The good and bad situation of the school students will directly affect the development of the development of the martial arts interest class and influence the birth of the reserve talents. However, due to some film and TV influence. In elementary school, martial arts are omnipotent, such as light work, point, etc. But once they learn martial arts through a period of time, they will find that their interest in kung fu fades when they are not satisfied. In view of this, we should reverse the current situation of the school and get the correct change in the concept of running a school, so as to pave the way for the inheritance and development of martial arts.

\section{The Research Object}

This article is aimed at the study of the object of the second primary school of hainan normal university, no.2 primary school of qiongshan district of hainan province, no. 3 primary school of qiongshan district, QiongShan area the second primary school of hainan province and hainan province QiongShan area the third primary school, hainanQiongShan area 5 primary school out 200 questionnaires, recycling, 195, 5 questionnaires is invalid.

\section{Research Results and Analysis}

The cognition of martial arts channel this article from the student, the student contact martial arts understanding of martial arts culture before and after comparison, the change of the primary school students interested in martial arts, martial arts interest class in primary school cause analysis, elementary school students to choose and teaching martial arts program suggested that the students agree with condition of martial arts teaching countermeasures to improve such aspects as study.

\subsection{Primary School Wushu Cognitive Channel}

By QiongShan area four primary schools in haikou city primary school students the channels of the cognition of martial arts, can reflect the haikouQiongShan area the distribution of martial arts interest class understanding of martial arts, is conducive to our better interest in martial arts to carry out the condition is put forward. 
Table 1. List of channel survey results of primary school students' martial arts cognition.

\begin{tabular}{ll}
\hline Cognitive channel & Proportion (\%) \\
\hline Hong Kong film (martial arts) & 70 \\
Domestic films (martial arts films) & 65 \\
TV program & 64.5 \\
Audio and video products (VCD, DVD) & 61.3 \\
The comic book & 57.5 \\
Cartoon & 55.2 \\
Wushu performance in major sports games & 53.6 \\
The martial arts performance of the campus large & 47.2 \\
group activities is & 37.5 \\
Park and other fitness sites & 32.2 \\
Martial arts novel & 31 \\
School publicity & 24.6 \\
Primary school physical education classroom teaching & 15 \\
A friend of the martial arts or a fellow countryman & 12 \\
Martial arts major books & 10.6 \\
Martial arts publications, magazines & 9.3 \\
Family education & \\
\hline
\end{tabular}

Table 1 provides us with a lot of interesting data. Accounts for the ratio of absolute advantage is the first Hong Kong martial arts film $70 \%$, accounted for $65 \%$ of domestic films, TV programs $(64.5 \%)$, audio and video products accounted for $61.5 \%$, cartoons comic books accounted for $57.5 \%$ and martial arts performances followed by large sports games. Most of the other channels are at an occasional frequency level, and five are at a basic level.

Secondly, from the cognitive channel frequency order, film and television programs ranked in the top three, that has an important influence on Pupils' basic cognitive film of martial arts; influence from primary school martial arts teaching channels, from the above data increasing trend, in the martial arts students heart is the true meaning of ornamental; The related books of martial arts have little influence on Pupils. This shows that the primary school students in the spare time under the premise of the premise, through the film and television has a basic understanding of martial arts, but did not become an active field of understanding of primary school students. In addition, pupils have more homework and take part in various interest classes, so they have more time to use. Through large-scale sports activities, park fitness facilities and the martial arts books contact martial arts understanding is less and less, which shows that professional martial arts books and martial arts publications influence on Pupils' influence is limited, the school publicity or go to the park to learn martial arts have little chance of parents teach the knowledge of martial arts is less.

\subsection{Comparative Analysis of Wushu Culture Before and After Contact with Wushu}

Table 2. The general cognition of the students in qiongshan district.

\begin{tabular}{ll}
\hline Survey problem & cognition degree \\
\hline Wushu is a sports program, and entertainment is very interesting & 2.81 \\
Wushu is the quintessence of national traditional culture, which is deeply loved by students & 2.81 \\
The people who are required to be in martial arts are great, and have great skill and envy & 2.71 \\
Martial arts are very mysterious and sophisticated & 2.67 \\
Wushu is a mysterious time, superstition color is thicker & 2.56 \\
Wushu is a learning and scientific discipline & 2.34 \\
Wushu is superior to other countries & 2.31 \\
Wushu has strict wude & 1.92 \\
The cultivation of martial arts people is good, modesty has interpersonal affinity & 1.82 \\
Wushu people have low cultural quality and arrogance & \\
\hline
\end{tabular}

According to table 2 of multiple-choice questions in the questionnaire result analysis, martial arts entertainment function and essence of the traditional culture in 2.81 the cognition of ranked first, martial arts skills account for 2.71 , wushu branches with accounts for 2.61, several other investigation without too much fluctuation.

From this, it can be seen that qiongshan primary school students are more approbation of the sports attribute, function and traditional culture characteristics of wushu. They think that martial arts people are very good, very good and admirable. As can be seen from table 2, the students of qiongshan district are more curious about the mysterious colors of martial arts, and have a strong sense of the fantasy and superstition of martial arts. But they are very much in favor of sports entertaining and interesting functional and national cultural essence, not very understanding martial arts and martial arts people's cultivation. However, they have low cultural quality to the martial arts people, and they are not very proud of their arrogance, which indicates that they are optimistic and approve of the cultivation of wushu people.

\subsection{Analysis of the Changes in the Interest of the Primary School Students}

Table 3. The intensity of the reasons for the interest of primary school students in qiongshan district.

\begin{tabular}{ll}
\hline Cause & Reasons for strength \\
\hline The martial arts itself is about unique attraction and entertainment & 2.63 \\
Teacher responsibility psychology, every class is required strict & 2.53 \\
The practice gains much, the fitness effect is obvious & 2.51 \\
The teacher is very amiable, recruit everybody to like & 2.50 \\
The classroom learning content is very attractive & 2.48 \\
The teacher gave a lively lecture and explained the demonstration very well $\backslash$ & 2.47 \\
\hline
\end{tabular}


According to students' questionnaire statistical results (table 3), occupy the first position is the attraction of wushu itself is 2.63, the second is the teachers' sense of responsibility, 2.53 fitness effect is 2.51 , the affinity of teachers, teaching contents, and the teacher's explanation model is $2.50,2.48,2.47$, respectively, indicating that the source of most of the students interested in martial arts, is through the martial arts unique attractive and entertaining, apparently in primary school students more attractive, entertaining than martial arts the true meaning of exercise and teachers' teaching content more persuasive. Second, it is to the teacher's affinity and the martial arts classroom to learn the way to change, to give affirmation. However, the teaching of wushu teachers is vivid, and the demonstration ability is not as important as the charm and entertainment of the martial arts.

\subsection{Reason Analysis of Primary School Martial Arts}

Table 4. Causes analysis of primary school students' martial arts interest class.

\begin{tabular}{lll}
\hline To carry out the status quo & Degree of identity & \\
\hline Other interest classes (drawing, chess, taekwondo) are preferred to the martial arts classes. & 2.63 \\
Parents and teachers have no intention of this & 2.53 \\
The school has carried out the education activity and education significance of wushu & 2.51 & 2.50 \\
PE teachers teach basic martial arts knowledge & 2.48 \\
Abundant teachers & 2.44 \\
There is no extra time to learn martial arts after class & \\
\hline
\end{tabular}

Martial arts from elementary school to carry out the analysis of the situation of statistical results (table 4), the questionnaire survey data is a fluctuation in the least, from 2.63 to 2.44 in total are zero, indicating that the current primary school martial arts classes to carry out the common problems in the computer.

Basis (table 4) shows that primary school students interest in martial arts less high than other interests, and parents and teachers don't have to let the child contact intention in this respect, the importance of school cannot popularize wushu to student's development, PE teacher without access to relevant basic knowledge. The school's teaching staff are relatively weak, not so perfect, the primary school after-school work and the time of the cram school is relatively compact, there is no extra time to learn martial arts. The most important thing is that students' interest in martial arts is not so high, but the main understanding is not enough.

\subsection{Primary School Students Are Advised to Choose Martial Arts and Teaching}

Mainly according to the results of questionnaire survey to help pupils at home long, statistical analysis, choose according to table 5 martial arts the purpose of distribution table shows, most selective stronger project is other accounts for 2.83, strengthen self defense, entertaining accounts for 2.45 , was admitted to the university through sports level of 2.22 , to participate in the martial arts competition won awards accounted for 2.10 , and the last two are respectively 1.95 and 1.90 .

Table 5. Chooses the distribution table of martial arts purpose.

\begin{tabular}{ll}
\hline Select the content & $\begin{array}{l}\text { Agree with } \\
\text { situation }\end{array}$ \\
\hline Carry forward the national culture of & 1.90 \\
Exercise physical fitness to enlist & 1.95 \\
Take part in a martial arts competition to win an award & 2.10 \\
Enter the university through the athlete hierarchy & 2.22 \\
Strong self-defense, entertainment & 2.45 \\
Other & 2.83 \\
\hline
\end{tabular}

Show pupils martial arts channel choice is blind, for national culture is not interested in martial arts, is given priority to with the ego need psychological, from one side shows that the essence of the martial arts attribute national culture spirit is far from other functions. To see things too one-sided, without really understanding the meaning of martial arts, and to try to learn to understand the state of mind, without thinking that martial arts will bring boundless gains to itself.

\subsection{The Students' Approval of the Improvement Countermeasures of Wushu Teaching}

Table 6. The approval of the improvement countermeasures of wushu teaching.

\begin{tabular}{ll}
\hline Improvements & Agree with degrees \\
\hline Add more games and interesting programs & 2.72 \\
Increase the interaction between teachers and students & 2.61 \\
Watch videos of high-level competitions and large-scale martial arts activities & 2.52 \\
Reduce the competitive colors of martial arts & 2.50 \\
Strengthen the study of martial arts culture & 2.50 \\
Improve the technical level and expression ability of teachers & 2.46 \\
Increase the number of teaching hours of martial arts & 2.32 \\
Strengthen the study of wushu theory & 2.28 \\
\hline
\end{tabular}


According to martial arts teaching countermeasures to improve the approval table (6) the results of the analysis, with 2.72 students to make link and the game more interesting link to compare agree that 2.61 is increase the interaction between teachers and students, the high level to watch the game accounted for 2.52 , reduce martial arts colour and strengthen wushu culture learning are respectively 2.50 , teachers' technical level of 2.46 , martial arts teaching hours 2.32, wushu theoretical study of 2.28 .

This illustrates the pupil corresponds to martial arts class game links and increase the interaction between teachers and students praise, most pupils born, fun and active form of martial arts class teaching not too many requirements. In order to properly arrange the appropriate number of class hours, students are in a less sympathetic position on the learning of martial arts teaching theory, and the students will agree or disagree with the general consent level on various Suggestions. This phenomenon indicates that it is imperative to cultivate and improve the interest of class and increase the interaction between teachers and students.

\section{Opinions on Martial Arts Teaching in Primary Schools}

\subsection{Stable and Deepen Students' Interest in Exercise}

The success of teaching is not about teaching and teaching, but about how to stimulate students' potential interests and strengthen them. Step by step how to make learning from the short interest into stable interest, causes the student to the pursuit of better martial arts and found that learning martial arts culture, carrying forward the national spirit, the martial arts as a compulsory course, which is the key to teaching.

\subsection{To Innovate and Improve the Quality of Teaching}

The conditions of the society changed, and the demands of The Times changed. The teaching of wushu also changed with the changes of The Times. We should find a way to teach the content of martial arts teaching that is easy for parents, teachers and students. For example, we have to know what the kids want to, what they need, they are more likely to accept what kind of way, all this as a starting point, on the basis of this, to develop a new and colorful martial arts teaching content. Lively and interesting teaching techniques, flexible and diverse teaching methods.

\subsection{Teachers and Students Exchange, Check Feedback and Consolidate Teaching Effect}

"The teacher, faith in his way," is the Confucius advocated and lifelong practice of a education teaching law. Therefore, in the classroom, teachers should pay attention to the elementary student's characteristics, pay attention to the release of feelings and inspiration, to praise more, points out that the advantages more, make the students psychological satisfaction, positive influence to motivate students, form a cohesive force and the force.

Assessment is an important means of teaching, but it is not the ultimate goal of martial arts. Primary school of martial arts programmes will is the beginning of martial arts education students contact, therefore, at the same time of examination, strengthen teaching effect, in order to better promote the formation of the concept of life-long martial arts, must adopt some effective methods of assessment, and thus achieve better teaching effect.

\subsection{Strengthen the Teaching of Qiongshan Primary School Martial Arts Interest Class}

In the survey, qiongshan primary school generally attached great importance to other interest classes, and ignored the culture of wushu and culture. Schools rarely wushu cultural activities held in the students, parents and school teachers have no intention in this regard, only attach importance to the cultivation of comprehensive quality of primary school pupils, pupils can be extended without interest in martial arts. Schools in importance to the cultural theory of learning, should make full use of the resources of the school and teachers, some martial arts wushu cultural activities and imparting knowledge, strengthen students understanding of martial arts. In addition, due to the influence of the long term heavy text, the leadership and the students generally not pay attention to the students' wushu culture knowledge and learn from the spirit of the essence of wushu. As a major training institution, the school must promote the education significance of wushu, expand the enrollment area of wushu class, and improve the quality of wushu talents in primary school. Therefore, schools should give full play to their advantages to expand enrollment.

\section{Conclusion}

Primary school students mainly rely on martial arts works to recognize martial arts, the contact surface is relatively narrow. Primary school students are very fond of martial arts, but not high in the recognition of wushu. The primary school students choose to learn the level of demand for martial arts interest. Most parents and teachers do not support the study. Even though students have the intention to do this, they have not received the strong support and attention from the school leaders. Select the purpose of learning a martial arts programmes will tend to entertainment, interest and other factors, for its own charm of wushu and national culture is not so clear, holding the superstition color and worship. The students have many expectations of the teaching contents, teaching method and the quality of teachers. To stabilize and deepen students' interest in practice, strengthen and stabilize students' interest. The choice of teaching content is narrow and unattractive. The teaching method is old and lacks scientific means. 


\section{References}

[1] The dilemma of Wushu education in primary and secondary schools [A]. Ji Jianfeng. The compilation of philosophy and social studies papers of the eighth academic conference of Jiangsu province [C]. 2014.

[2] China's primary and middle schools of martial arts education research [A]. Kang Sidney govou, Hong Hao. The Eighth National Sports Science conference abstracts (1) [C]. 2007.

[3] Under the background of school Wushu education hundred years development of [A]. Ma Erhao, Xing Wentao. 2015 the tenth national sports science conference abstracts (three) [C]. 2015.

[4] Analysis of the difficulties and Countermeasures of Wushu education in primary and secondary schools [A]. Song Hui. "Peer" (September 2015) ([C]. 2015).

[5] Martial arts in the development of sports confusion [A]. to Wen Jun. 2016 January modern education and teaching exploration Symposium Symposium [C].

[6] Primary school martial arts promotion mode construction -Based on the "5W" mode of [A]. Han Qingsong's. 2015 the tenth national sports science conference abstracts (two) [C]. 2015.

[7] Of Guilin city middle school martial arts teaching present situation and countermeasure analysis of $[\mathrm{J}]$. Liu Zhongqin,

Zhang Xuchang. The world of sports (Academic Edition) $2010(08)$.

[8] On the Wushu curriculum in middle school to carry out the status quo of Tang Jianying [J].. The scientific advisory (education and Research) 2013 (12).

[9] Regression of martial arts nature -- from the technical orientation of China's small and medium-sized martial arts curriculum design [J]. Zhang Feng, Zhao Guangsheng, Ji Lin Hong. Journal of Shanghai Institute of Physical Education $2014(03)$

[10] Li Lin feng. Research on wushu activities in jiangxi province [D]. East China jiaotong university. 2012.

\section{Biography}

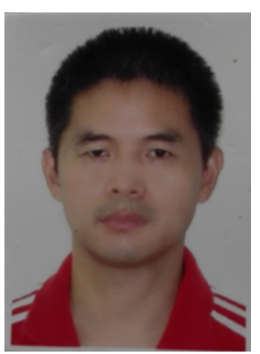

Zhuang Changkuan hainan normal university 2015 Research on the operation of large-scale sports events in the construction of international tourism island and the research on the development mode of sports events in the construction of international tourism island. HNSKC9YB) 15-110. 